\title{
Female gender may predict response to FOLFIRINOX in patients with unresectable pancreatic cancer: A single institution retrospective review
}

\author{
FLORIAN HOHLA $^{1 *}$, GEORG HOPFINGER ${ }^{1 *}$, FRANZ ROMEDER ${ }^{1}$, GABRIEL RINNERTHALER $^{1}$, \\ ANGELIKA BEZAN $^{1}$, STEFAN STÄTTNER ${ }^{2}$, CORNELIA HAUSER-KRONBERGER $^{3}$, \\ HANNO ULMER $^{4}$ and RICHARD GREIL ${ }^{1}$
}

\begin{abstract}
${ }^{1}$ Third Medical Department with Hematology, Medical Oncology, Hemostaseology, Rheumatology and Infectious Diseases, Oncologic Center, Center for Clinical Cancer and Immunology Trials, Laboratory of Immunological and Molecular Cancer Research, ${ }^{2}$ Surgical Department, ${ }^{3}$ Department of Pathology, Paracelsus Medical University of Salzburg, A-5020 Salzburg; ${ }^{4}$ Department of Medical Statistics, Informatics and Health Economics, Innsbruck Medical University, A-6020 Innsbruck, Austria
\end{abstract}

Received August 25, 2013; Accepted October 15, 2013

DOI: 10.3892/ijo.2013.2176

\begin{abstract}
FOLFIRINOX is a highly active regimen for the treatment of patients with unresectable pancreatic cancer. However, treatment with FOLFIRINOX is associated with relevant toxicity and predictors for response to therapy are warranted. We retrospectively analyzed 49 patients with unresectable pancreatic cancer treated with FOLFIRINOX in order to evaluate a possible predictive role of clinical parameters and tumor characteristics for response to chemotherapy. Tumor samples were characterized histopathologically before treatment and expression of p53 and Ki67 was analyzed using automated immunohistochemistry. Overall survival (OS) and progression-free survivall (PFS) were estimated by the KaplanMeier method. The overall objective response rate was $55.1 \%$, the disease control rate was $70.6 \%$. Female gender was associated with a significantly higher disease control rate of 91.7 compared to $48.0 \%$ in male patients $(\mathrm{p}=0.001$ ) which reached $100 \%$ in
\end{abstract}

Correspondence to: Dr Florian Hohla, Third Medical Department with Hematology, Medical Oncology, Hemostaseology, Rheumatology and Infectious Diseases, Oncologic Center, Center for Clinical Cancer and Immunology Trials, Laboratory of Immunological and Molecular Cancer Research, Paracelsus Medical University of Salzburg, Müllner Hauptstrasse 48, A-5020 Salzburg, Austria

E-mail: f.hohla@salk.at

${ }^{*}$ Contributed equally

Abbreviations: CTX, chemotherapy; BMI, body mass index; $\mathrm{PR}$, partial remission; $\mathrm{SD}$, stable disease; $\mathrm{PD}$, progressive disease; APC, advanced pancreatic cancer; CEA, carcinoembryogenic antigen; CA19.9, carboanhydrase 19.9

Key words: pancreatic cancer, FOLFIRINOX, chemotherapy, female gender, predictive markers, p53, Ki67 female patients when primarily treated compared to treatment after surgical resection and relapse $(77.8 \%, \mathrm{p}=0.057)$. For all patients median PFS was 3.5 months (95\% CI, 2.7-4.3 months) and median OS was 13 months (95\% CI, 9.4-16.6 months). Female patients showed a tendency towards a longer median PFS (5.0 months, 95\% CI, 3.6-6.4 months) compared to males (3.0 months, 95\% CI, 2.4-3.6 months) ( $\mathrm{p}=0.099)$. Serum levels of CA19.9 and CEA were significantly higher in female patients compared to male patients $(\mathrm{p}=0.037, \mathrm{p}=0.05)$. Tumors of patients with response to FOLFIRINOX showed a higher expression level of p53 and Ki67 as well as higher serum levels of CA19.9 compared to non-responders, which was statistically not significant. Our study indicates that female gender is a positive predictor for therapy response to FOLFIRINOX in patients with unresectable pancreatic cancer. Female gender in turn was associated with increased levels of tumor markers CEA and CA19.9 and patients with higher serum levels of CA19.9 were more responsive to FOLFIRINOX.

\section{Introduction}

Pancreatic cancer is the fourth leading cause of cancer-related death in men and women (1). Up to $85 \%$ of patients are diagnosed at an advanced stage when the tumor is unresectable because of infiltration of local arteries or distant metastasis (2). Gemcitabine has been the standard of care for the treatment of advanced pancreatic cancer based on a randomized trial showing an improvement in the one-year survival with gemcitabine compared to 5-fluorouracil (5-FU) (3). Although well-tolerated, the efficacy of gemcitabine is modest, with reported response rates (RR) of $10 \%$ and median survival of less than 7 months (3). The combination of gemcitabine with a variety of cytotoxic and targeted agents has generally shown no significant survival advantage as compared to gemcitabine alone (4). Some studies have suggested a significant benefit in overall survival (OS) and progression-free survival (PFS) 
associated with gemcitabine-based cytotoxic combinations in patients with good performance status $(5,6)$. An impressive efficacy and longer median OS of 10.2 months was first reported in a phase II study in patients with advanced pancreatic cancer under treatment with the combination regimen FOLFIRINOX (oxaliplatin, irinotecan, 5-FU and leucovorin) (7). Subsequently, FOLFIRINOX was compared to gemcitabine in a randomized phase III trial in patients with advanced pancreatic cancer (8). This study confirmed statistically significant and clinically relevant improvements in OS (11.1 vs. 6.8 months), PFS (6.4 vs. 3.3 months) and RR (31.6 vs. 9.4\%) with FOLFIRINOX compared to gemcitabine alone. Because of significant higher grade 3 and 4 toxicities (mostly neutropenia, diarrhea, febrile neutropenia, thrombocytopenia, sensory neuropathy) with FOLFIRINOX and the limited survival time of patients with advanced pancreatic cancer, biomarkers allowing a better patient selection are required. Therefore, the aim of our study was to assess clinical (age, body mass index, gender), histopathological [histology, grading, tumor location, T-stage, levels of carboanhydrase 19.9 (CA19.9) and carcinoembryogenic antigen (CEA), p53 and Ki67 expression] parameters of patients with advanced pancreatic cancer treated with FOLFIRINOX and their association with response to treatment.

\section{Materials and methods}

Study design and assessment of response. We conducted a retrospective review of all patients with either primarily locally advanced, metastatic or recurrent unresectable pancreatic cancer treated with FOLFIRINOX at our department between October, 2010 and November, 2012. We evaluated patient and tumor characteristics such as gender, age, age adapted body mass index (BMI), performance status, T-stage according to the TNM classification, initial tumor localization (the head vs. the body, tail or the papilla of the pancreas) and primary metastases (hepatic, peritoneal, pulmonal) or localization of relapse (local vs. visceral metastasis) based on review of the patients' medical records. Response was assessed by review of the patients imaging studies according to RECIST criteria as complete (CR), partial response (PR), stable disease (SD) or progressive disease (PD) as well as by tumor marker response of CA19.9 (9). Thus, a decrease or increase in CA19.9 by $50 \%$ compared to baseline after treatment was classified as PR or PD, respectively. The objective response rate was defined as the percentage of patients with CR and PR. The disease control rate was defined as the percentage of patients with CR, PR and SD (Table I).

Treatment. Full dose FOLFIRINOX consisted of oxaliplatin $85 \mathrm{mg} / \mathrm{m}^{2}$ over $3 \mathrm{~h}$, followed by irinotecan $180 \mathrm{mg} / \mathrm{m}^{2}$ over $90 \mathrm{~min}$ and leucovorin $400 \mathrm{mg} / \mathrm{m}^{2}$ over $2 \mathrm{~h}$, followed by $5-\mathrm{FU}$ $400 \mathrm{mg} / \mathrm{m}^{2}$ as a bolus and 2,400 $\mathrm{mg} / \mathrm{m}^{2}$ as a $46 \mathrm{~h}$ continuous infusion. Dose modifications due to toxicity were made according to the discretion of the treating physician. Treatment was discontinued in case of unacceptable toxicity, progression of disease or pursuit of alternative therapies including surgical resection or radiotherapy for locally advanced disease (Fig. 1).

Immunohistochemistry. Immunohistochemical staining for Ki67 and p53 protein was performed using the antibodies monoclonal mouse anti-human Ki67 (clone MIB-1, Dako, Glostrup, Denmark) at a working dilution of 1:500 and monoclonal mouse anti-human p53 (clone DO-7, Dako) at a working dilution of 1:200 on routinely formalin-fixed paraffin embedded (FFPE) tissue, using a standardized automated platform (AutostainerPlus, Dako) in combination with Envision polymer detection system (Dako). Archival FFPE sections (3 $\mu \mathrm{m})$ were deparaffinized in combination with heat-induced epitope retrieval (HIER) at $98^{\circ} \mathrm{C}$ for $40 \mathrm{~min}$ in antigen retrieval buffer pH 9.0 (Dako) in a PT Link ${ }^{\mathrm{TM}}$-module (Dako). Endogenous peroxidase blocking was carried out for $10 \mathrm{~min}$ with $3 \% \mathrm{H}_{2} \mathrm{O}_{2}$ in absolute methanol and normal serum was applied. Primary antibodies and detection reagents were incubated at RT for 30 min and after several washes detection was performed using EnvisionFlex ${ }^{\mathrm{TM}}$ detection system, followed by chromogenic visualisation with diaminobenzidine (DAB) for $10 \mathrm{~min}$. Nuclear counterstaining was performed with hematoxylin. Assessment of Ki67 and p53 staining was performed according to the recommendations of the International Ki67 in Breast Cancer working group (10). At least three high-power (x40 objective) fields and clear hot spots were selected to represent the spectrum of staining seen and 100 cancer cells were evaluated.

CA19.9 and CEA measurement. CA19.9 and CEA measurements were carried out at a certified laboratory associated with the hospital by an electrochemiluminescence immunoassay (Roche Diagnostics, Mannheim, Germany). The upper limit normally used for CA19.9 was $37 \mathrm{U} / \mathrm{ml}$ and for CEA $3.5 \mu \mathrm{g} / \mathrm{l}$. Serum levels of CA19.9 and CEA were measured before therapy and every second week during therapy.

Statistics. Baseline and clinicopathological characteristics were summarized as median and range for continuous variables and as absolute and relative frequencies for categorical variables. Comparisons in regard to gender and therapy response were either performed with the Kruskal-Wallis, the Mann-Whitney $\mathrm{U}$ or the $\chi^{2}$ test. P-values $<0.05$ were considered to indicate statistical significance. Tumor markers were correlated with each other using Spearman rank correlation coefficient. A multivariate logistic regression model was performed to assess the joint effect of gender, age and clinical variables such as tumor stage, line of treatment (primary treatment vs. treatment in the relapsed stage) and biomarkers such as Ki67 and p53 on the response rate. OS and PFS were estimated using the KaplanMeier method together with the log-rank test. As survival measures, median and $95 \%$ confidence intervals are given.

\section{Results}

Characteristics of the patients. Between October 2010 and November 2012 a total of 52 patients with either locally advanced non-metastatic $(n=6)$, metastatic $(n=31)$ or relapsed unresectable pancreatic cancer after initial resection $(n=15)$ were treated with FOLFIRINOX at our department (Fig. 1). Two patients discontinued CTX after the first application due to grade 3 toxicities (1 febrile neutropenia, 1 diarrhea) or cancer related complications ( 1 patient with ileus) and therefore were excluded from our analysis. Thus, a total of 49 patients could finally be included in our study. Demographic and tumor 
Table I. Demographic and baseline characteristics of all the patients.

\begin{tabular}{|c|c|}
\hline Characteristics & \\
\hline Gender, no. (\%) & \\
\hline Male & $24 \quad(49)$ \\
\hline Female & $25 \quad(51)$ \\
\hline Age, years & \\
\hline Median & 62 \\
\hline Range & $42-76$ \\
\hline BMI & \\
\hline Median & 22.3 \\
\hline Range & $17.2-34.8$ \\
\hline ECOG performance score 0, no. $(\%)$ & $49(100)$ \\
\hline Histology, no. (\%) & \\
\hline Adenocarcinoma & $42(95.5)$ \\
\hline Giant cell carcinoma & $1(2.3)$ \\
\hline Adenosquamous carcinoma & 1 (2.3) \\
\hline No histology & $5 \quad(10)$ \\
\hline Grading & \\
\hline 2 & $28(65.1)$ \\
\hline 3 & $15(34.9)$ \\
\hline Pancreatic tumor localization, no. (\%) & \\
\hline Head & $24(49.0)$ \\
\hline Body & $7(14.3)$ \\
\hline Tail & $16(32.7)$ \\
\hline Papilla vateri & $2(4.1)$ \\
\hline T-stage & \\
\hline 2 & $3(6.7)$ \\
\hline 3 & $26(57.8)$ \\
\hline 4 & $16(35.6)$ \\
\hline Non-metastatic disease, no. (\%) & $6(12.2)$ \\
\hline Metastatic disease, no. (\%) & $28(57.1)$ \\
\hline Metastatic sites & \\
\hline Liver & $15(53.6)$ \\
\hline Liver/peritoneum & $8(28.6)$ \\
\hline Lung & $4(14.3)$ \\
\hline Liver/lung & $4(14.3)$ \\
\hline Relapsed disease, no (\%) & $15(30.6)$ \\
\hline Locoregional & 1 (6.7) \\
\hline Visceral (liver, lung, periteonal) & $7(46.7)$ \\
\hline Locoregional and visceral & $7(46.7)$ \\
\hline
\end{tabular}

ECOG, Eastern Cooperative Oncology Group; BMI, body mass index.

parameters were equally distributed between both genders (Table II). Although female patients showed higher numbers of metastatic tumors (15 vs. 13) and no locally advanced non-metastatic tumors before treatment compared to males ( 0 vs. 6 months) $(\mathrm{p}=0.095)$, they were characterized by significant higher levels of CA19.9 $(\mathrm{p}=0.037)$ and CEA $(\mathrm{p}=0.05)$.

Efficacy of FOLFIRINOX in the whole study population and according to gender. Based on the imaging studies of the patients as well as tumor marker response we confirmed a PR and SD in $27(55.1 \%)$ and $7(14.3 \%)$ patients, respectively. There were no complete remissions (CR). Fifteen out of 49 patients (30.6\%) patients did not respond to a CTX with FOLFIRINOX and were classified as PD (Table III). When response rates were analyzed according to gender, a significantly higher objective response rate, defined as patients with either CR or PR, of 75 vs. $36 \%(\mathrm{p}=0.004)$ as well as a higher disease control rate defined as patients with either PR or SD of 91.7 vs. $48 \%(\mathrm{p}=0.001)$ was seen in female patients compared to male patients (Table III). The predictive effect of gender on the response rate remained statistically significant $(\mathrm{p}=0.041)$ in the multivariate logistic regression analysis adjusting for age, tumor stage, line of treatment, Ki67 and p53. Two female patients with metastatic disease as well as 2 male patients with locally advanced disease were able to undergo resection (Fig. 1).

Efficacy of FOLFIRINOX in primarily treated and relapsed pancreatic carcinomas. Disease control rates in the whole study population did not differ significantly when RRs were assessed in untreated patients compared to patients after surgical resection and treatment in the relapsed stage (70.6 vs. $66.7 \%$ ). However, when patients were analyzed according to gender and line of treatment, in women FOLFIRINOX caused a disease control rate of $100 \%$ in the first-line setting compared to $77.8 \%$ in the relapsed stage ( $\mathrm{p}=0.057)$. Male patients showed a significantly lower disease control rate of $47.4 \%$ after firstline treatment than females $(\mathrm{p}=0.001)$. Their response rates in first-line and treatment in the relapsed stage (50\%) did not differ $(\mathrm{p}=0.670)($ Table IV).

Progression-free and overall survival. Survival data are shown in Table $\mathrm{V}$ and Fig. 2. For the entire cohort of patients the median PFS was 3.5 months (95\% CI, 2.7-4.3 months) with a median OS of 13 months (95\% CI, 9.4-16.6 months). Despite significantly higher response rates, female patients showed only a tendency towards a longer median PFS of 5 months compared to 3 months in male patients $(\mathrm{p}=0.09)$ (Fig. 2A). The median OS did not significantly differ between female (15 months, 95\% CI, 6.5-23.5 months) and male patients (12 months, 95\% CI, 9.7-14.3 months) $(\mathrm{p}=0.20)$ (Fig. 2B).

Clinicopathological characteristics and their association with response to treatment with FOLFIRINOX. There was no significant associations of either age, BMI, serum levels of CA19.9 and CEA or expression of p53 and Ki67 in pancreatic tumors with response to FOLFIRINOX (Table VI). However, tumors of patients with PR to FOLFIRINOX showed a tendency towards a higher expression of Ki67 and p53 as well as higher levels of CA19.9 compared to resistant tumors. In univariate analysis CA19.9 levels were significantly associated with the expression of $\mathrm{Ki} 67$ ( $\mathrm{p}=0.017, \mathrm{r}=0.39$ ) (data not shown).

\section{Discussion}

Most patients with pancreatic cancer are either unresectable at diagnosis or will suffer from a relapse after initial surgery, resulting in a 5-year OS of $6 \%$ (11). The median OS of patients with advanced or metastatic pancreatic cancer is 6 months with most chemotherapeutic options (4). Treatment with FOLFIRINOX has offered a new option for patients with 
Table II. Demographic and baseline characteristics of female vs. male patients.

\begin{tabular}{|c|c|c|c|}
\hline Characteristics & Female $(n=24)$ & Male $(n=25)$ & P-value \\
\hline \multicolumn{4}{|l|}{ Age, years } \\
\hline Median & 61 & 63 & \multirow[t]{2}{*}{0.603} \\
\hline Range & $42-73$ & $45-76$ & \\
\hline \multicolumn{4}{|l|}{ BMI } \\
\hline Median & 22.3 & 22.9 & \multirow[t]{2}{*}{0.379} \\
\hline Range & $17.2-34.8$ & $17.3-30-7$ & \\
\hline \multicolumn{4}{|l|}{ Level of carbohydrate antigen 19.9} \\
\hline Median & 2494 & 185 & \multirow[t]{2}{*}{ 0.037 } \\
\hline Range & $0-140241$ & $0-32266$ & \\
\hline \multicolumn{4}{|l|}{ Level of carcinoembryogenic antigen } \\
\hline Median & 10.4 & 5.7 & \multirow[t]{2}{*}{0.05} \\
\hline Range & $2-363$ & $2-306$ & \\
\hline \multicolumn{4}{|c|}{ Level of Ki-67 positive cancer cells (\%) } \\
\hline Median & 30 & 20 & \multirow[t]{2}{*}{0.457} \\
\hline Range & $1-80$ & $1-70$ & \\
\hline \multicolumn{4}{|l|}{ Level of mutant p53 cancer cells (\%) } \\
\hline Median & 30 & 1 & \multirow[t]{2}{*}{0.147} \\
\hline Range & $1-100$ & $0-90$ & \\
\hline \multicolumn{4}{|l|}{ Histology, no. (\%) } \\
\hline Adenocarcinoma & $22(100)$ & $20(90.9)$ & \multirow[t]{3}{*}{0.351} \\
\hline Giant cell carcinoma & $0 \quad(0)$ & $1(4.5)$ & \\
\hline Adenosquamous carcinoma & $0 \quad(0)$ & $1 \quad(4.5)$ & \\
\hline \multicolumn{4}{|l|}{ Grading } \\
\hline 2 & $14(63.6)$ & $14(66.7)$ & \multirow[t]{2}{*}{0.835} \\
\hline 3 & $8(36.4)$ & $7(33.3)$ & \\
\hline \multicolumn{4}{|l|}{ Pancreatic tumor location, no. (\%) } \\
\hline Head & $12 \quad(50)$ & $12(48.0)$ & \multirow[t]{4}{*}{0.946} \\
\hline Body & $4(16.7)$ & $3(12.0)$ & \\
\hline Tail & $7(29.2)$ & $9(36.0)$ & \\
\hline Papilla Vateri & 1 (4.2) & $1 \quad(4.0)$ & \\
\hline \multicolumn{4}{|l|}{ T-stage } \\
\hline 2 & 1 (4.8) & $2(8.3)$ & \multirow[t]{5}{*}{0.063} \\
\hline 3 & $16(76.2)$ & $10(41.7)$ & \\
\hline 4 & 4 (19) & $12(50.0)$ & \\
\hline Non-metastatic disease, no. (\%) & $0 \quad(0)$ & $6(24.0)$ & \\
\hline Metastatic disease, no. (\%) & $15(62.5)$ & $13(52.0)$ & \\
\hline \multicolumn{4}{|l|}{ Metastatic sites, no. (\%) } \\
\hline Liver & $9(60.0)$ & $6(46.2)$ & \multirow[t]{4}{*}{0.466} \\
\hline Liver/peritoneum & $4(26.7)$ & $4(30.7)$ & \\
\hline Lung & $2(13.3)$ & $2(15.4)$ & \\
\hline Liver/lung & $3(20.0)$ & $1 \quad(7.7)$ & \\
\hline Relapsed disease, no (\%) & $9(37.5)$ & $6(24.0)$ & 0.629 \\
\hline Locoregional & $1(11.1)$ & $0 \quad(0.0)$ & \\
\hline Visceral (liver, lung, periteonal) & $4(44.4)$ & $3(50.0)$ & \\
\hline Locoregional/visceral & $4(44.4)$ & $3(50.0)$ & \\
\hline
\end{tabular}

BMI, body mass index. Bold text, statistically significant.

advanced pancreatic cancer and a good performance status (8). However, it was reported that a considerable percentage of patients, up to $50 \%$, treated with FOLFIRINOX experienced grade 3 and 4 toxicities $(7,8)$. Understanding the features that determine response or resistance to this chemotherapy regimen could permit the selection of the most suitable patients for 


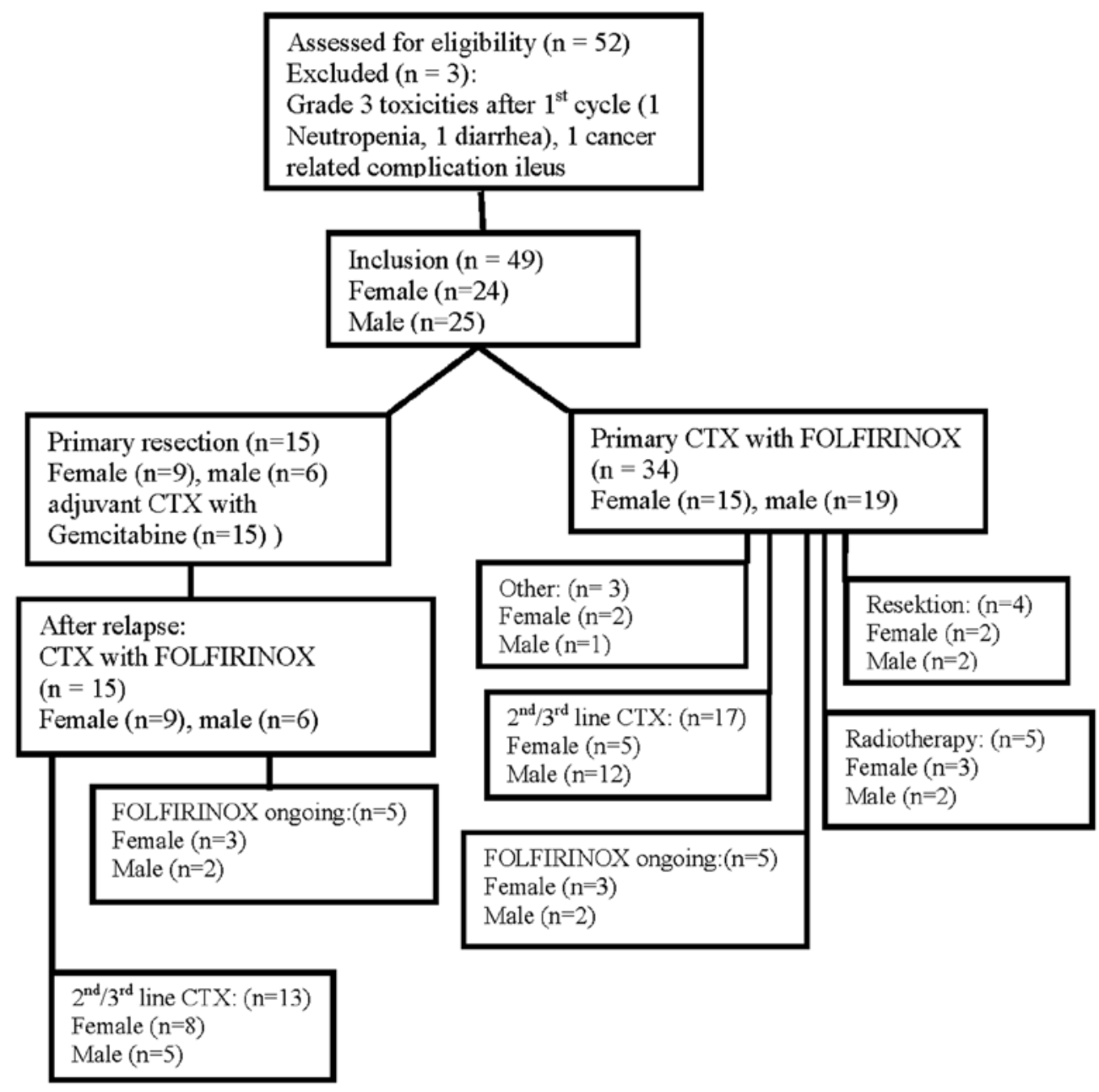

Figure 1. Consort diagram of the study population.
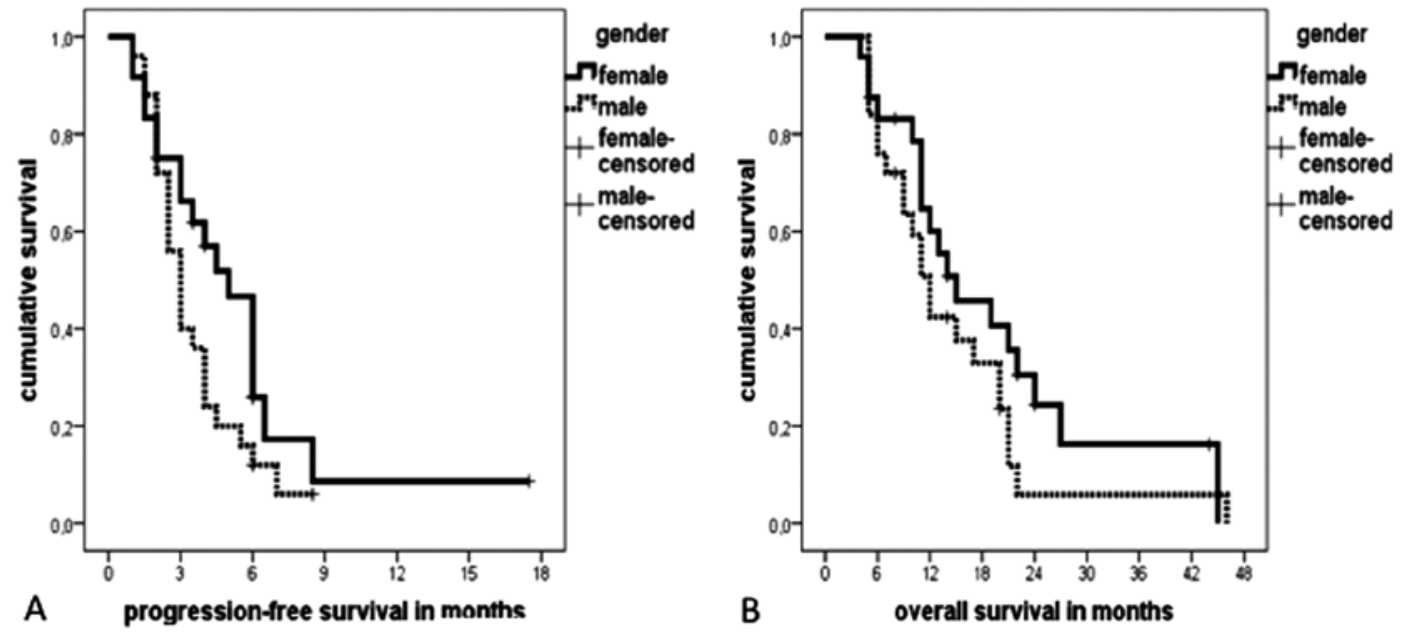

Figure 2. Kaplan-Meier survival estimates of (A) progression-free survival and (B) overall survival of female patients (solid line) and male patients (dotted line).

treatment with FOLFIRINOX. Thus, in our study, we evaluated clinical and histological markers and their associations with response to FOLFIRINOX.
The objective response rate, defined as the percentage of patients with CR and PR, was slightly higher (55.1\%) in our overall study population compared to the $32 \%$ reported by 
Table III. Response rates in all patients and in patients allocated according to gender (female vs. male).

\begin{tabular}{|c|c|c|c|}
\hline Variable & Total $(n=49)$ & & \\
\hline \multicolumn{4}{|c|}{ Response, no. (\%) } \\
\hline $\mathrm{CR}$ & $0 \quad(0)$ & & \\
\hline PR & $27(55.1)$ & & \\
\hline $\mathrm{SD}$ & $7(14.3)$ & & \\
\hline $\mathrm{PD}$ & $15(30.6)$ & & \\
\hline \multicolumn{4}{|c|}{$\begin{array}{l}\text { Rate of disease } \\
\text { control }(\mathrm{PR}+\mathrm{SD})\end{array}$} \\
\hline No. (\%) & $34(69.4)$ & & \\
\hline Variable & Female $(n=24)$ & Male $(n=25)$ & P-value \\
\hline \multicolumn{4}{|c|}{ Response, no. (\%) } \\
\hline PR & $18 \quad(75)$ & $9(36)$ & 0.004 \\
\hline $\mathrm{SD}$ & 4 (16.7) & $3(12)$ & \\
\hline PD & $2(8.3)$ & $15(52)$ & \\
\hline \multicolumn{4}{|c|}{$\begin{array}{l}\text { Rate of disease } \\
\text { control }(\mathrm{PR}+\mathrm{SD})\end{array}$} \\
\hline No. $(\%)$ & $22(91.7)$ & $12(48)$ & 0.001 \\
\hline
\end{tabular}

Conroy et al (8). This might be explained by the fact that in our highly selected study population all patients $(100 \%)$ exhibited an ECOG performance status (PS) 0 whereas the majority (61\%) of patients in the historical group of Conroy et al had an ECOG PS 1. Higher response rates of $45 \%$ compared to the historical data of Conroy et al were also obtained in another retrospective analysis performed by Gunturu et al (12). This study population also consisted of a higher percentage of patients $(69 \%)$ with an ECOG PS 0.
Table IV. Efficacy of FOLFIRINOX in primary and relapsed pancreatic carcinomas.

\begin{tabular}{lcl}
\hline Primary treatment & All patients $(\mathrm{n}=34)$ & P-value \\
\hline Response, no. $(\%)$ & \\
PR+SD & $24(70.6)$ \\
PD & $10(29.4)$
\end{tabular}

Female $(\mathrm{n}=15) \quad$ Male $(\mathrm{n}=19)$

\begin{tabular}{lrrrr}
\hline Response, no. (\%) & & & & \\
PR+SD & $15(100)$ & $9(47.4)$ & $\mathbf{0 . 0 0 1}$ \\
PD & 0 & $(0)$ & $10(52.6)$ &
\end{tabular}

Treatment relapsed

stage All patients $(n=15) \quad$ P-value

$\begin{array}{lr}\text { Response, no. }(\%) & \\ \text { PR+SD } & 10(66.7) \\ \text { PD } & 5(33.3)\end{array}$

\begin{tabular}{lrrr}
\hline & Female $(\mathrm{n}=9)$ & Male $(\mathrm{n}=6)$ & \\
\hline $\begin{array}{l}\text { Response, no. (\%) } \\
\text { PR+SD }\end{array}$ & $7(77.8)$ & $3(50)$ & 0.064 \\
PD & $2(22.2)$ & $3(50)$ &
\end{tabular}

$\mathrm{CR}$, complete remission; $\mathrm{PR}$, partial remission; $\mathrm{SD}$, stable disease; $\mathrm{PD}$, progressive disease.

The percentage of patients with SD reported by Conroy et al was higher compared to our study population (39 vs. $14.3 \%$ ). Therefore, a similar disease control rate, defined as percentage of patients with $\mathrm{CR}, \mathrm{PR}$ or $\mathrm{SD}$, could be seen in our study compared to historical data (69.4 vs. 70\%) (8).

Table V. Median progression-free and overall survival.

Progression-free survival

median, months $(95 \% \mathrm{CI})$
Overall survival

median, months $(95 \% \mathrm{CI})$

Overall study population

$\begin{array}{ll}\text { All patients }(\mathrm{n}=49) & 3.5(2.7-4.3) \\ \text { Female }(\mathrm{n}=25) & 5.0(3.6-6.4) \\ \text { Male }(\mathrm{n}=24) & 3.0(2.4-3.6) \\ \text { Primary treatment } & \\ \text { All patients }(\mathrm{n}=34) & 4.0(2.7-5.3) \\ \text { Female }(\mathrm{n}=15) & 5.0(3.5-6.5) \\ \text { Male }(\mathrm{n}=19) & 3.0(2.3-3.7) \\ \text { Treatment relapsed stage } & \\ \text { All patients }(\mathrm{n}=15) & 3.0(1.6-4.4) \\ \text { Female }(\mathrm{n}=9) & 3.5(2.0-5.0) \\ \text { Male }(\mathrm{n}=6) & 2.0 \quad(\mathrm{n} . \mathrm{a} .)\end{array}$

13 (9.4-16.6)

$15 \quad(6.5-23.5)$

12 (9.7-14.3)

11 (9.9-12.0)

11 (9.3-12.7)

$11 \quad(1.3-8.4)$

21 (19.1-22.9)

22 (19.1-24.9)

$20(12.8-27.2)$

n.a., not applicable. 
Table VI. Clinicopathological characteristics and their association with response to treatment with FOLFIRINOX.

\begin{tabular}{lccc}
\hline Variable & PR & PD & P-value \\
\hline $\begin{array}{l}\text { Ki-67 expression (\%) } \\
\quad \text { Median }\end{array}$ & 25 & 17.5 & 0.328 \\
$\quad$ Range & $1-80$ & $1-70$ & \\
$\begin{array}{l}\text { Mutant p53 } \\
\text { expression (\%) }\end{array}$ & & & \\
$\quad$ Median & 20 & 5.5 & 0.422 \\
$\quad$ Range & $0-100$ & $1-90$ & \\
$\begin{array}{l}\text { Level of } \\
\text { carbohydrate antigen 19.9 } \\
\text { Median }\end{array}$ & 1612 & 1322 & 0.529 \\
$\quad$ Range & $1-140241$ & $0-32266$ & \\
$\begin{array}{l}\text { Level of carcino- } \\
\text { embroygenic antigen }\end{array}$ & & & \\
$\quad \begin{array}{l}\text { Median } \\
\text { Range }\end{array}$ & 7 & 7.45 & 0.752 \\
$\begin{array}{l}\text { Age, years } \\
\text { Median }\end{array}$ & $2-363$ & $2-306$ & \\
$\quad$ Range & & & \\
Body mass index & 61 & 63 & 0.783 \\
$\begin{array}{l}\text { Median } \\
\text { Range }\end{array}$ & $42-73$ & $46-69$ & \\
\hline
\end{tabular}

PR, partial remission; PD, progressive disease.

When RRs were assessed according to gender a highly significant difference in response to FOLFIRINOX could be seen between the female and male treatment groups. As shown in Table III, there was a significant higher percentage of female patients with PR (75\%) compared to males (36\%) $(\mathrm{p}=0.004)$ leading to a significantly $(\mathrm{p}=0.001)$ higher disease control rate in female patients (91.7 vs. $48.0 \%$ ). To our knowledge, this is the first study reporting different response rates to CTX according to gender in patients with pancreatic cancer. Although we could see a tendency towards a longer median PFS in female patients (5 months) compared to males ( 3 months) $(p=0.099)$ significantly higher response rates did not cause a significant difference in the median OS between female and male patients (15 vs. 12 months) $(\mathrm{p}=0.200)$ (Table V, Fig. 2). This might be explained by the small sample size as well as the fact, that there was a higher number of locally advanced non-metastatic tumors in male patients compared to females (6 vs. 0$)(\mathrm{p}=0.095)$ (Table II). Patients with locally advanced pancreatic tumors are known to have a longer median OS of 15.7 months than patients with metastatic pancreatic tumors (9.5 months) (7). Thus, the higher number of locally advanced pancreatic tumors in male patients might have nullified the benefit of higher response rates in female patients. Retrospective analyses should be viewed with caution and causes for the improved RR to FOLFIRINOX in the female study population remain speculative. Demographic and baseline disease characteristics were well-balanced and did not differ significantly between the female and male group in our study. CA19.9 is the most extensively studied and validated biomarker for the diagnosis of pancreatic cancer (13). Despite its limitations as false negative results in sialyl Lewis negative individuals and false positive elevation in the presence of obstructive jaundice CA19.9 serum levels as well as a reduction in CA19.9 levels during treatment have prognostic and predictive value (13). It has been reported that patients with pretreatment levels lower than median showed a better tumor response to neoadjuvant radiochemotherapy with 5-FU or adjuvant CTX with gemcitabine $(14,15)$. There are no data so far regarding the predictive value of pretreatment levels of CA19.9 and response to CTX with FOLFIRINOX. In our patients serum levels of CA19.9 ( $\mathrm{p}=0.037)$ and CEA $(0.05)$ were significantly higher in female patients compared to males (Table II). There was a tendency of higher serum levels of CA19.9 (median 1,612 vs. 1,322 U/ml) in tumors of objective responders (PR) compared to patients with PD (Table V). However, the difference did not reach significance probably because of the limited sample size. While an association of response to CTX and the rate of Ki67 in breast cancer as well some gastrointestinal cancers has been reported, data in pancreatic cancer for Ki67 as a potential predictive marker for response CTX cancer are lacking (16-19). The proliferation rate of tumor cells as defined by Ki67 was higher in responders vs. non-responders (median 25.0 vs. 17.5\% positive cells) in our patients. In univariate analysis of our cohort, CA19.9 serum levels were significantly associated with the expression of Ki67 in univariate analysis $(\mathrm{p}=0.017$, $\mathrm{r}=0.39$, data not shown).

Despite its central role in the control of apoptosis, senescence and cell cycle arrest, the tumor suppressor protein p53 remains an enigma for its possible role in predicting response to chemotherapy in cancer patients. Mutant p53 proteins generally have an increased stability and accumulate in the nucleus of tumor cells and may be detectable by immunohistochemistry. It is believed that this is a consequence of the inactive p53 mutant protein not inducing the MDM2 protein required to target its own degradation (20). The status of p53 is associated with cancer cell resistance to various chemotherapeutics $(21,22)$. Wild-type p53 is thought to render tumors more sensitive to treatment by the induction of apoptosis, and p53 inactivation may lead to resistance to treatment. However, because p53 is also responsible for prolonged cell cycle arrest after chemotherapy-induced genetic damage, it is expected to facilitate DNA repair in the absence of an apoptotic response. Therefore tumors that inactivate p53 might be less capable of DNA repair and more sensitive to a DNA damage-induced mitotic catastrophe as reported in gastric cancer (23). In our cohort of patients p53 staining was increased in responders as compared to non-responders ( 20.0 vs. $5.5 \%$ positive cells, Table VI), although this difference was not statistically significant. The role of p53 in predicting response to FOLFIRINOX in pancreatic cancer patients will have to be studied in a larger cohort of patients.

The results of our study indicate, that female gender could positively predict response to FOLFIRINOX in patients with advanced pancreatic cancer. The predictive value of serum levels of CA19.9 and expression of p53 and Ki67 in advanced pancreatic tumors require further substantiation. 


\section{References}

1. Siegel R, Naishadham D and Jemal A: Cancer statistics, 2012 CA Cancer J Clin 62: 10-29, 2012.

2. Lefebvre AC, Maurel J, Boutreux S, et al: Pancreatic cancer: incidence, treatment and survival trends - 1175 cases in Calvados (France) from 1978 to 2002. Gastroenterol Clin Biol 33: 1045-1051, 2009.

3. Burris HA III, Moore MJ, Andersen J, et al: Improvements in survival and clinical benefit with gemcitabine as first-line therapy for patients with advanced pancreas cancer: a randomized trial. J Clin Oncol 15: 2403-2413, 1997.

4. Di Marco M, Di Cicilia R, Macchini M, et al: Metastatic pancreatic cancer: is gemcitabine still the best standard treatment? (Review). Oncol Rep 23: 1183-1192, 2010.

5. Cunningham D, Chau I, Stocken DD, et al: Phase III randomized comparison of gemcitabine versus gemcitabine plus capecitabine in patients with advanced pancreatic cancer. J Clin Oncol 27: 5513-5518, 2009.

6. Moore MJ, Goldstein D, Hamm J, et al: Erlotinib plus gemcitabine compared with gemcitabine alone in patients with advanced pancreatic cancer: a phase III trial of the National Cancer Institute of Canada Clinical Trials Group. J Clin Oncol 25: 1960-1966, 2007.

7. Conroy T, Paillot B, Francois E, et al: Irinotecan plus oxaliplatin and leucovorin-modulated fluorouracil in advanced pancreatic cancer - a Groupe Tumeurs Digestives of the Federation Nationale des Centres de Lutte Contre le Cancer study. J Clin Oncol 23: 1228-1236, 2005.

8. Conroy T, Desseigne F, Ychou M, et al: FOLFIRINOX versus gemcitabine for metastatic pancreatic cancer. N Engl J Med 364: 1817-1825, 2011.

9. Therasse P, Arbuck SG, Eisenhauer EA, et al: New guidelines to evaluate the response to treatment in solid tumors. European Organization for Research and Treatment of Cancer, National Cancer Institute of the United States, National Cancer Institute of Canada. J Natl Cancer Inst 92: 205-216, 2000.

10. Dowsett M, Nielsen TO, A'Hern R, et al: Assessment of Ki67 in breast cancer: recommendations from the International Ki67 in Breast Cancer working group. J Natl Cancer Inst 103: 1656-1664, 2011.

11. Sant M, Allemani C, Santaquilani M, Knijn A, Marchesi F and Capocaccia R: EUROCARE-4. Survival of cancer patients diagnosed in 1995-1999. Results and commentary. Eur J Cancer 45: 931-991, 2009.
12. Gunturu KS, Yao X, Cong X, et al: FOLFIRINOX for locally advanced and metastatic pancreatic cancer: single institution retrospective review of efficacy and toxicity. Med Oncol 30: 361, 2013.

13. Ballehaninna UK and Chamberlain RS: The clinical utility of serum CA 19-9 in the diagnosis, prognosis and management of pancreatic adenocarcinoma: An evidence based appraisal. J Gastrointest Oncol 3: 105-119, 2012.

14. Micke O, Bruns F, Kurowski R, et al: Predictive value of carbohydrate antigen 19-9 in pancreatic cancer treated with radiochemotherapy. Int J Radiat Oncol Biol Phys 57: 90-97, 2003.

15. Humphris JL, Chang DK, Johns AL, et al: The prognostic and predictive value of serum CA19.9 in pancreatic cancer. Ann Oncol 23: 1713-1722, 2012.

16. Fasching PA, Heusinger K, Haeberle L, et al: Ki67, chemotherapy response, and prognosis in breast cancer patients receiving neoadjuvant treatment. BMC Cancer 11: 486, 2011.

17. Zhang GC, Qian XK, Guo ZB, et al: Pre-treatment hormonal receptor status and Ki67 index predict pathologic complete response to neoadjuvant trastuzumab/taxanes but not diseasefree survival in HER2-positive breast cancer patients. Med Oncol 29: 3222-3231, 2012.

18. Carlomagno C, Pepe S, D'Armiento FP, et al: Predictive factors of complete response to neoadjuvant chemoradiotherapy in patients with rectal cancer. Oncology 78: 369-375, 2010.

19. Ressiot E, Dahan L, Liprandi A, et al: Predictive factors of the response to chemoradiotherapy in esophageal cancer. Gastroenterol Clin Biol 32: 567-577, 2008.

20. Soussi T: p53 alterations in human cancer: more questions than answers. Oncogene 26: 2145-2156, 2007.

21. Sax JK and El-Deiry WS: p53 downstream targets and chemosensitivity. Cell Death Differ 10: 413-417, 2003.

22. Bertheau P, Espie M, Turpin E, et al: TP53 status and response to chemotherapy in breast cancer. Pathobiology 75: 132-139, 2008.

23. Bataille F, Rummele P, Dietmaier W, et al: Alterations in p53 predict response to preoperative high dose chemotherapy in patients with gastric cancer. Mol Pathol 56: 286-292, 2003. 